\title{
STRUCTURAL REHABILITATION USING HIGH DAMPING RUBBER BEARING (HDRB)
}

\author{
Ali Vatanshenas ${ }^{1}$, Takahiro Mori² and Nobuo Murota ${ }^{3}$
}

(Submitted June 2020; Reviewed August 2020; Accepted October 2020)

\begin{abstract}
High damping rubber bearings show highly nonlinear stress-strain behaviour. Deformation-history integral (DHI) model which can estimate small strain stiffness degradation and nonlinear plasticity via a relatively simple innovative formulation is implemented in this study to model HDRB as the rehabilitation method for a seismically vulnerable building. Considered structure in this study is a three-dimensional, four-story steel frame residential building with a concentrically braced system. Nonlinear direct integration time history analysis and plastic hinges approach were implemented to evaluate structural behaviour of considered structure. It was observed that structural responses enhanced significantly after rehabilitation. Absolute maximum base shear values decreased $61.8 \%$ and $92.2 \%$ in the worst and best cases, respectively. Most of structural elements remained elastic after rehabilitation and required performance level was satisfied.
\end{abstract}

\section{INTRODUCTION}

Malaysian Rubber Producers' Research Association of the United Kingdom introduced a rubber material that had adequate damping characteristic that omitted the demand for additional damping systems attached to bearings [1]. Proposed material showed nonlinear decaying shear stiffness and damping trends in the early strain amplitudes. At large strains this trend changes in such a way that stiffness escalates because of crystallization of material which goes along with rise in energy absorption. This enhanced behaviour in terms of stiffness and damping ends up with a more stable condition under loading cases with uncertainty. Moreover, due to high damping characteristic of HDRB, this bearing is suitable for decreasing traffic and railway high-frequency oscillations [2]. Stiffness degradation and damping trend of HDRB including its unique stress-strain behaviour under lateral dy namic loading is presented in Figure 1. As far as the authors know, implementation of HDRB as a rehabilitation tool has not been investigated before. Besides, lack of a robust constitutive model that captures significant nonlinear properties of HDRB made engineers conservative regarding using HDRB. Therefore, authors decided to discuss suitability of DHI model and HDRB via comparing results of a vulnerable structure under two cases of with and without HDRB in this paper.

Highly nonlinear plastic behaviour of HDRB distinguishes it from other conventional seismic isolators like lead rubber and friction bearings. Previous studies tried to model this complicated behaviour via nonlinear rate dependency approaches [3]. However, analy tical modelling of this complex stress-strain behaviour is not a trivial task [4-6]. DHI model is formulated for HDRB element and recently implemented in finite element programs SAP2000 and ETABS [7], to capture different trends of behaviour within a simple constitutive model as shown in Figure 2. Detailed formulation of this model is discussed in the next section.

\section{FORMULATION OFDHI MODEL}

In this section, organized formulation process of DHI model for bidirectional loading is presented by reviewing relevant literature [8-12]. This model is formulated as a modified version of Simo's model (Equation 1) [13]. In this equation, $S$ is second Piola-Kirchhoff stress, $W_{v o l}$ is volumetric part of elastic stored energy function, $\bar{W}_{d e v}$ is deviatoric part of elastic stored energy, $C$ is right Cauchy-Green tensor, $g_{n}$ is a variable that controls the magnitude of energy absorption, $\bar{W}_{0}$ is strain energy density function for deviatoric deformation related to viscosity, $\tau_{n}$ is relaxation time of $\mathrm{n}^{\text {th }}$ element and $n$ is the number of springs. In DHI model, parameter $t$ in Simo's model is replaced with the curvilinear integral $I$ along the deformation orbit $x$ (Equation 2) where $D^{\prime}$ is the deviatoric part of deformation rate tensor. Modified equation is presented in Equation 3, Where $L$ is the incremental accumulated strains given by Equation $4\left(L_{n}\right.$ is the relaxation of $n^{\text {th }}$ spring).

By considering damage effects on the material's behaviour Equation 5 is achieved, in which $\Xi$ is the damage function. This equation is formulated in six degrees of freedom. Therefore, this relation was rearranged to be applicable as a bidirectional analytical model suitable for dynamic loading applications (Equation 6). Formulation of $\tau^{\mathrm{e}}$ and $\tau^{\mathrm{h}}$ which are elasticity and hy steretic components of shear stress are discussed in the next paragraph in detail.

$S=2 \frac{\partial \mathrm{W}_{v o l}}{\partial \mathrm{C}}+2 \frac{\partial \bar{W}_{d e v}}{\partial \mathrm{C}}+2 \sum_{n=1}^{N} g_{n} \int_{0}^{t} \frac{d}{d t^{\prime}}\left(\frac{\partial \bar{W}_{0}}{\partial \mathrm{C}}\right) e^{\frac{-\left(t-t^{\prime}\right)}{\tau_{n}}} d t^{\prime}$

$\left\ulcorner=\int_{0}^{t} \sqrt{\frac{2}{3} D^{\prime}: D^{\prime}} d t\right.$

$S=2 \frac{\partial W_{v o l}}{\partial C}+2 \frac{\partial \bar{W}_{d e v}}{\partial C}+2 \sum_{n=1}^{N} g_{n} \int_{0}^{L} \frac{d}{d \Gamma^{\prime}}\left(\frac{\partial \bar{W}_{0}}{\partial C}\right) e^{\frac{-\left(\Gamma-\Gamma^{\prime}\right)}{L n}} d \Gamma^{\prime}$

$L=\int_{x} \sqrt{d r_{2}^{2}+d r_{3}^{2}}$

$S=2 \frac{\partial \mathrm{W}_{v o l}}{\partial \mathrm{C}}+2 \Xi \frac{\partial \bar{W}_{d e v}}{\partial \mathrm{C}}+2 \sum_{n=1}^{N} g_{n} \int_{0}^{L} \frac{d}{d \Gamma^{\prime}}\left(\frac{\partial \bar{W}_{0}}{\partial \mathrm{C}}\right) e^{\frac{-\left(\mathrm{r}-\mathrm{r}^{\prime}\right)}{L n}} d \Gamma^{\prime}$

$\tau=\tau^{\mathrm{e}}+\sum_{n=1}^{N}\left[\tau^{\mathrm{h}}\right]_{n}$

${ }^{1}$ Corresponding Author, Doctoral Researcher, Tampere University, Tampere, ali.vatanshenas@tuni.fi

${ }^{2}$ Chief Researcher, Bridgestone Corporation, Seismic Isolation and Vibration Control Products Development Department, Yokohama takahiro.moril@bridgestone.com

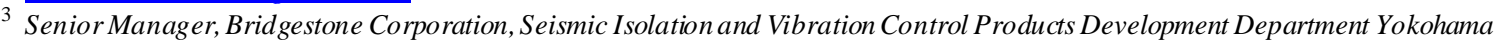
nobuo.murota@bridgestone.com 

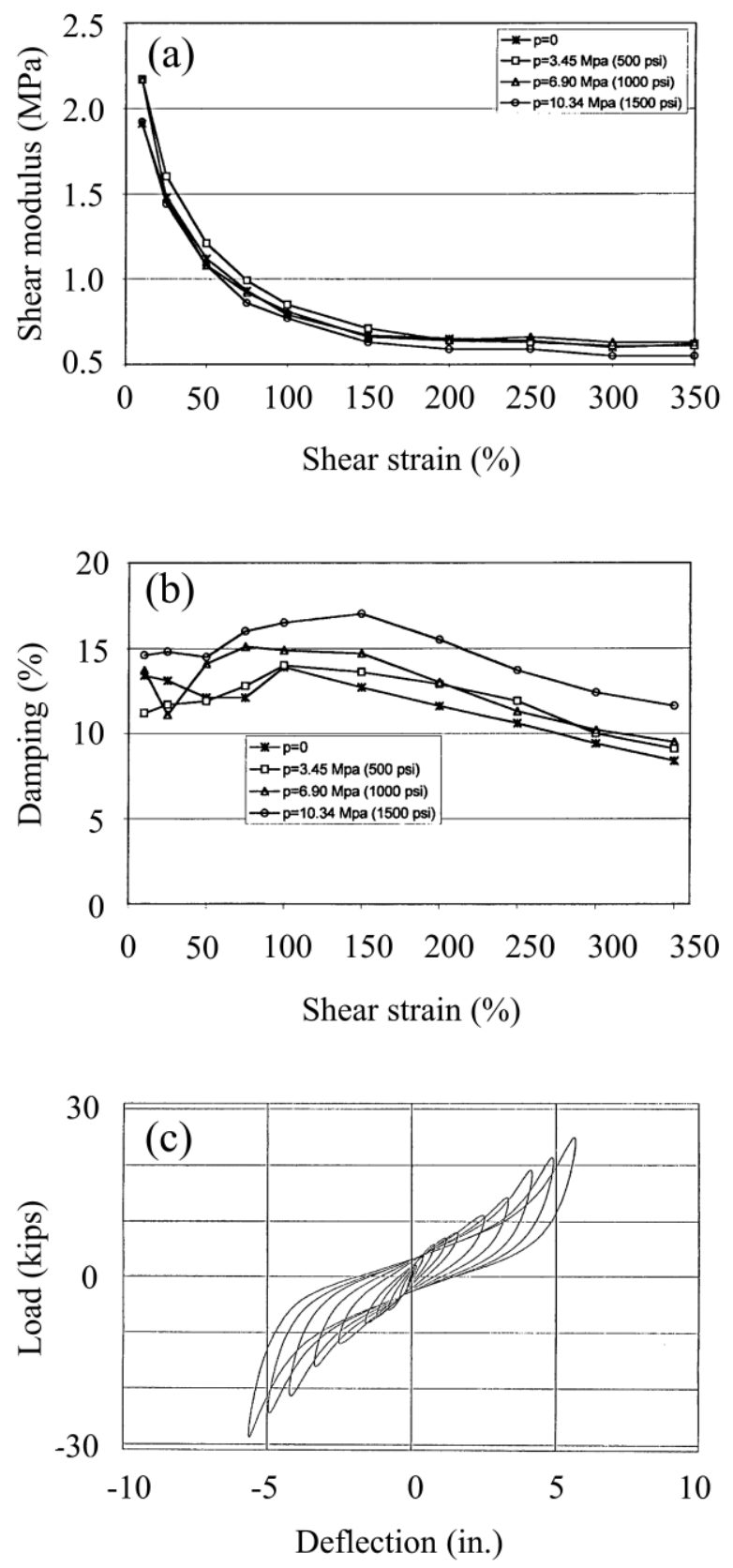

Figure 1: Stiffness reduction (a), damping (b) and highly nonlinear hysteresis (c) trends of HDRB [2].

To better understanding of $\tau^{\mathrm{e}}$ and $\tau^{\mathrm{h}}$ relations in the following consider Figure 3, where coordinate system and model's schematic is shown. One of the main advantages of DHI model is considering small strain stiffness and its degradation. In this model, elasticity was derived by Equations $7 \mathrm{a}$ and $7 \mathrm{~b}$ for both horizontal directions in which $G_{a}$ is the parameter governing initial stiffness and $\Xi$ is given by Equation 8. In this equation, $\theta$ and $\bar{Y}_{d}$ are resistance ratio and control strain, respectively. In addition, $r_{\max }$ is the factor calculated from maximum experienced shear strain. It is the maximum length of strain in $\Upsilon_{2}-r_{3}$ plane given by Equation 9. Note that since $r_{\max }$ is dependent on both lateral directions, damage function takes into account damage in both horizontal directions. Damage function is proportional to both resistance ratio and control strain, which means decrease in any of these parameters, results in considering more damage to the model. In general, by inserting all the relevant parameters into Equations $7 \mathrm{a}$ and $7 \mathrm{~b}$, elasticity will take the explicit form presented in Equations 10a and 10b. Moreover, shear stress of the $i^{\text {th }}$ hysteretic component is calculated via Equations $11 \mathrm{a}$ and $11 \mathrm{~b}$, where $\bar{Y}_{i}$ and $\bar{\tau}_{i}$ are hysteretic control strain and strength, respectively.
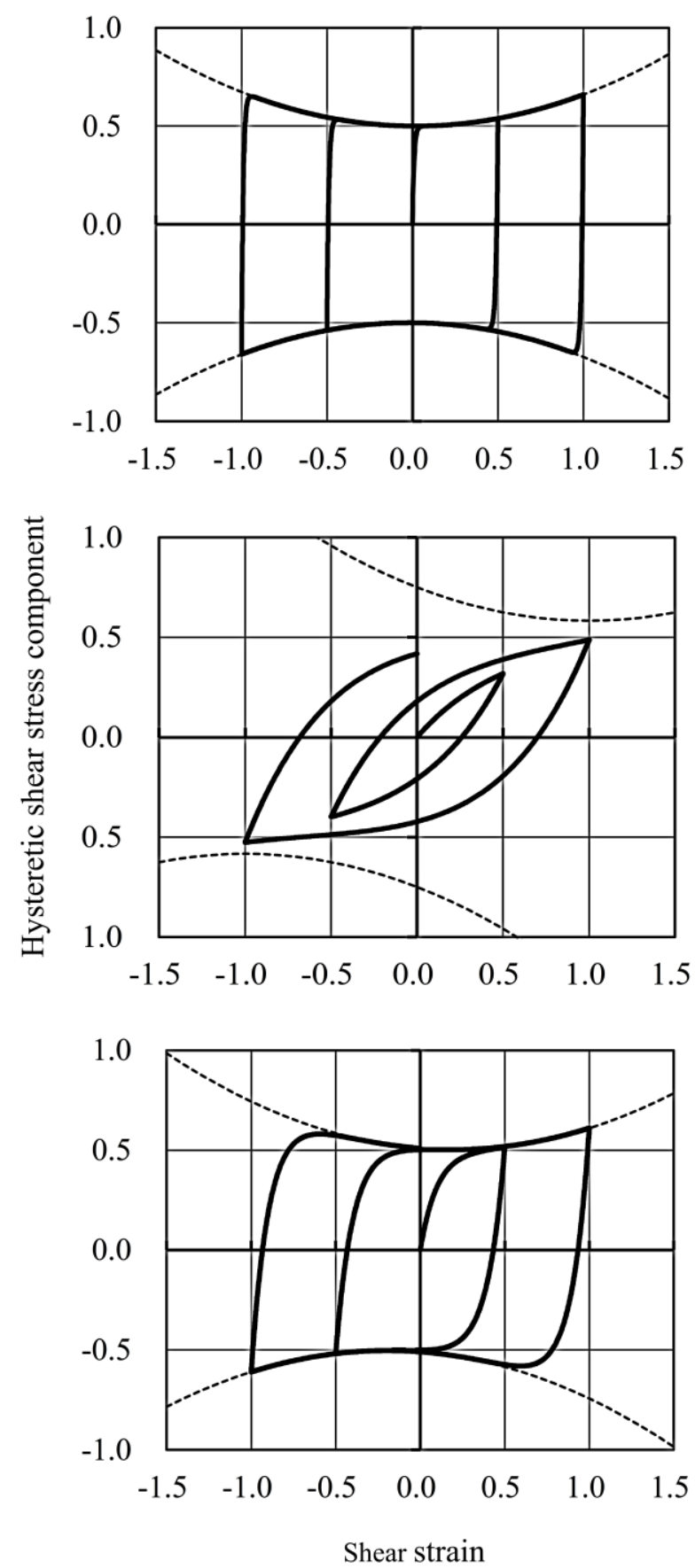

Figure 2: Feasible trends of hysteresis behaviour within a constant constitutive model modified from [12].

$\tau_{2}^{e}=G_{a} \Xi \Upsilon_{2}^{e}$

$\tau_{3}^{e}=G_{a} \Xi Y_{3}^{e}$

$\Xi=\theta+(1-\theta) e^{-\left(\frac{r_{\max }}{r_{d}}\right)}$

$\Upsilon_{\max }=\max _{c}\left(\sqrt{{\Upsilon_{2}{ }^{2}+Y_{3}^{2}}^{2}}\right.$

$\tau_{2}^{e}=G_{a}\left[\theta+(1-\theta) e^{-\left(\frac{\max _{c}\left(\sqrt{r_{2}^{2}+r_{3}^{2}}\right)}{r_{d}}\right)}\right] Y_{2}^{e}$

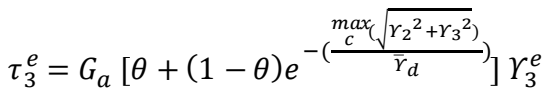

$\left[\tau_{2}^{h}\right]_{i}=\frac{\bar{\tau}_{i}}{3} \int_{x} \frac{d}{d L^{\prime}}\left[\left(\Upsilon_{2}^{\prime}-\Upsilon_{2}\right)\left(Y_{2}^{\prime^{2}}+{\Upsilon_{3}^{\prime}}^{2}\right)+3 \Upsilon_{2}^{\prime}\right] e^{\frac{L-L^{\prime}}{Y_{i}}} d L^{\prime}$

$\left[\tau_{3}^{h}\right]_{i}=\frac{\bar{\tau}_{i}}{3} \int_{x} \frac{d}{d L^{\prime}}\left[\left(\Upsilon_{3}^{\prime}-\Upsilon_{3}\right)\left(Y_{3}^{\prime^{2}}+{Y_{2}^{\prime}}^{2}\right)+3 Y_{3}^{\prime}\right] e^{\frac{L-L^{\prime}}{Y_{i}}} d L^{\prime}$ 

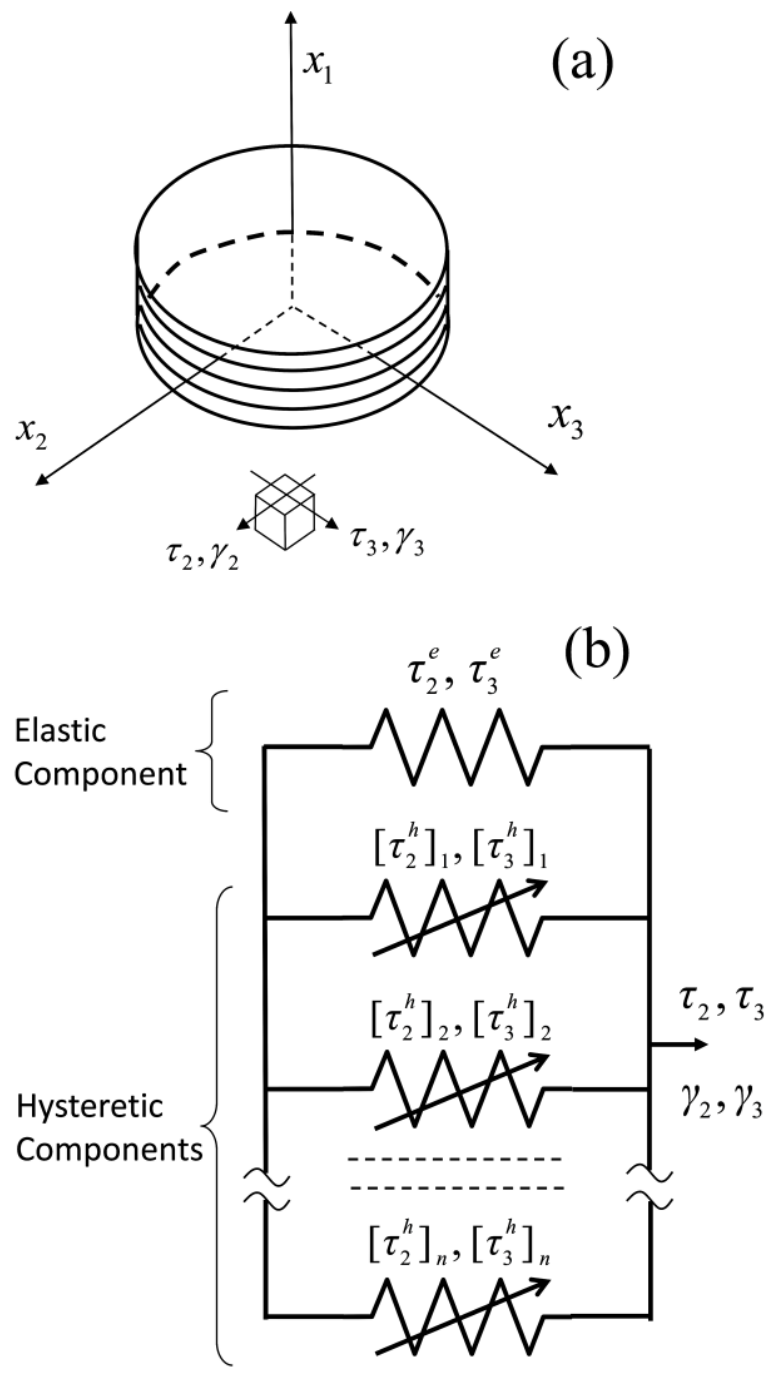

Figure 3: (a) Coordinate system; and (b) DHI model schematic modified from [12].

\section{NONLINEAR ANALYSIS AND STRUCTURAL VULNERABILITY}

In general, nonlinear analysis is classified in three main categories of finite element (FE), fiber, and plastic hinge methods where the latter is faster but less accurate (Figure 4) Selecting appropriate subgroup depends on desired output, accuracy and computational effort. FEM and fiber methods are more suitable for microscale problems where behaviour of an individual element is studied. However, in this study investigation of a macroscale problem (i.e behaviour of the whole structure: base shear, drift, etc.) is discussed. Therefore, plastic hinge approach is a more logical choice.

As shown in Figure 4, to use plastic hinge method of analy sis, the element behaviour is needed as input. Thus, it is important to understand the elements' behaviour. In short, the behaviour of a structural element is dependent on its type (i.e. column, beam, brace, etc.) and the bearing force type (i.e. tension, compression, shear, etc.) (see Figure 5).

In general, regulations propose that ductile and brittle behaviours be analysed using displacement control (DC) and force control (FC) approaches, respectively. However, the control criteria can be contradictory to the elements' behaviour under certain conditions. For instance, the behaviour of a column element under tension is ductile but its control can be FC. This means that design codes impose stricter criteria on important elements like columns whose failure is more crucial on stability of the whole structure.

In general, rehabilitation is defined as balancing demand and capacity. Conventional approaches like jacketing methods focus on increasing the capacity of vulnerable buildings while rehabilitation by reducing demand (i.e. implementing seismic isolation systems) are usually neglected. Moreover, rehabilitation is only required if the desired performance level is not reached. In short, performance levels are qualitative descriptions of quantified parameters presented in codes like [14]. Performance levels are illustrated schematically in Figure 6, where IO, LS, and CP stand for immediate occupancy, life safety, and collapse prevention.

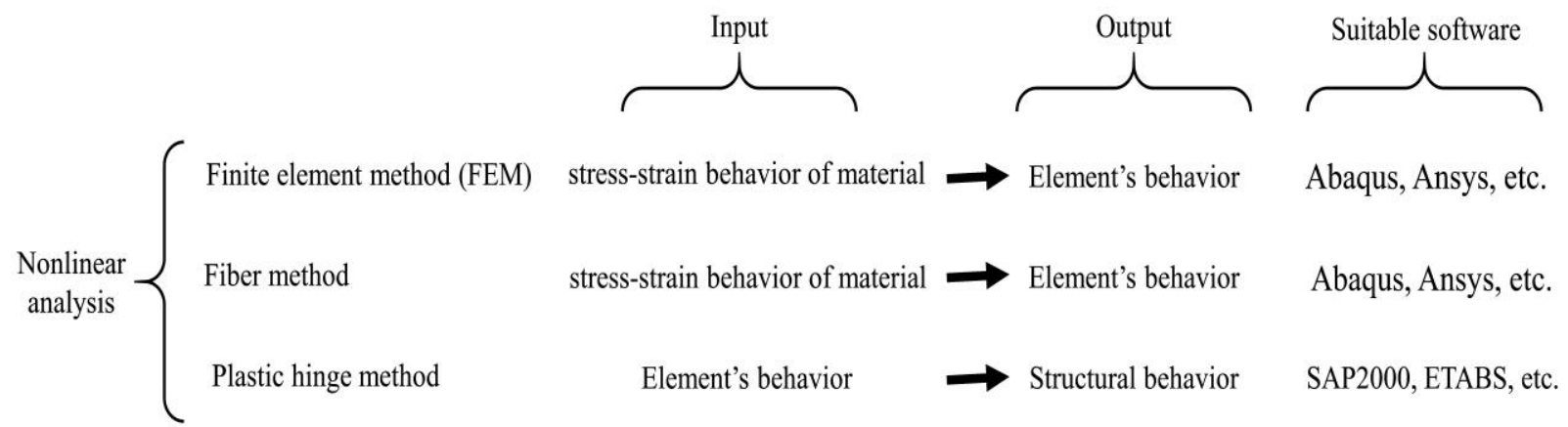

Figure 4: Classification of nonlinearanalysis methods.

Element type

(i.e. column, beam, brace, etc.)

Force type

(i.e. tension, compression, shear, etc.)

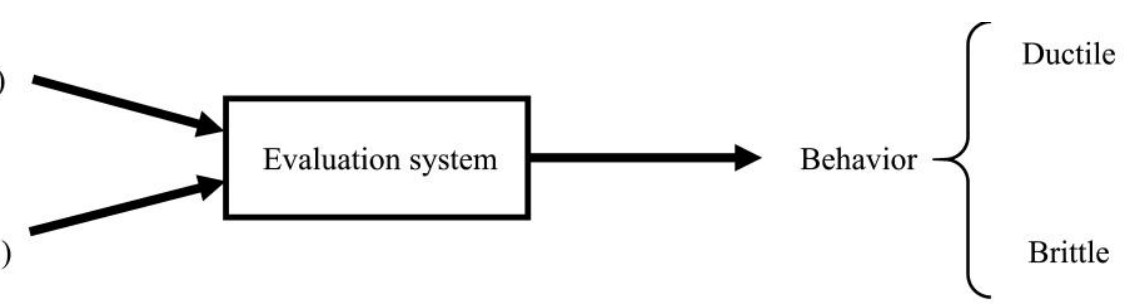

Figure 5: Evaluation system for defining structural behaviour for elements. 


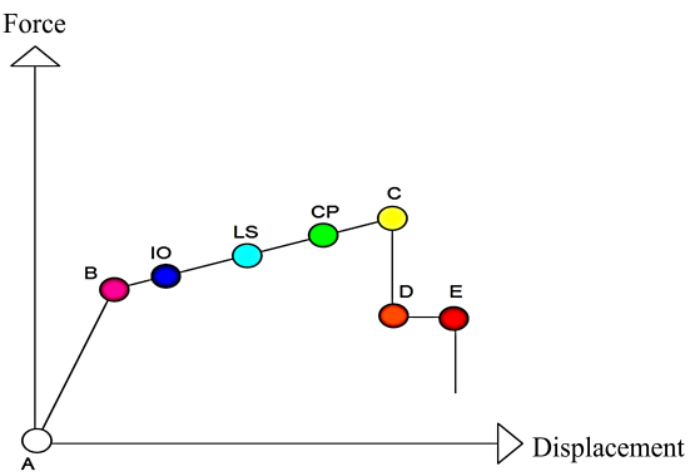

Figure 6: Performance levels.

As shown in this figure, performance levels refer to the structure's response after yielding. Therefore, designed structures are allowed to enter plastic region, but only until reaching a certain limit specified by regulations. The structure considered in this study is a three-dimensional, four-story steel frame residential building with a concentrically braced system. This building is expected to satisfy LS performance level, but its vulnerability assessment conducted using pushover analy sis in SAP2000 in previous studies [15] showed that the building does not meet the required performance level and rehabilitation is needed in both $\mathrm{X}$ and $\mathrm{Y}$ directions (Figure 7). Note that the structural system of the building is a concentrically braced frame, not a moment frame, and the governing loads in this type of structure are uniformly distributed axial loads in the primary elements. As a result, only axial hinges were assigned to the primary structural elements. For brevity, more details regarding vulnerability assessment of this building is referred to [15].

\section{RESULTS AND DISCUSSIONS}

In this section, the isolators' properties, lateral loading protocol used in the analysis and rehabilitation results are presented.
Nonlinear direct integration time history analy sis was chosen to investigate the efficiency of HDRB as a rehabilitation technique under real earthquake loadings. SAP2000 software was utilized for modelling the building under consideration with and without the HDRB isolators. Time history analysis is significantly dependent on the selected dynamic loadings. Earthquake science with all its uncertainties has two general rules: "repetition" and "similarity". Repetition means that if an earthquake occurs on a site, possibility of another earthquake occurring in the future remains unaltered and similarity indicates that usually earthquakes occurring in a special site have similar characteristics [16]. Therefore, lateral loadings considered in this study are seven pairs of near field earthquake ground motion records which have similar characteristics in terms of magnitude, fault type, distance to epicentre and soil type (presented in Table 1).

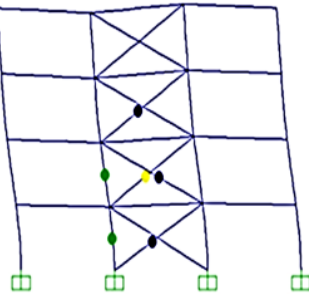

(a)

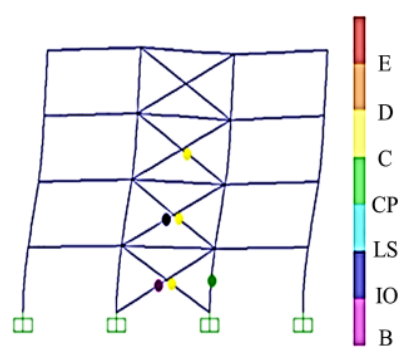

(b)
Figure 7: Plastic hinges created via pushover analysis: $X$ direction (a) and Y direction (b), modified from [15].

Sixteen HDRB isolators were attached beneath the vulnerable structure. Despite the fact that vertical static loading on bearings differ based on their installation place, due to simplicity and symmetrical plan of the structure only one type of HDRB element was implemented. Parameters chosen for the HDRB element used in this study are shown in Table 2.

Table 1: Selected earthquake records.

\begin{tabular}{|c|c|c|c|c|c|c|c|}
\hline Event & Year & Station & Magnitude & Fault type & $\mathbf{R j b}(\mathbf{k m})$ & $\mathbf{V}_{\mathrm{s}}(\mathbf{m} / \mathbf{s})$ & PGA (g) \\
\hline Helena & 1935 & Carroll College & 6.0 & strike slip & 2.07 & 593.35 & 0.161 \\
\hline Victoria & 1980 & Cerro Prieto & 6.33 & strike slip & 13.8 & 471.53 & 0.298 \\
\hline Morgan Hill & 1984 & Anderson Dam & 6.19 & strike slip & 3.22 & 488.77 & 0.423 \\
\hline Chalfant Valley & 1986 & Bishop - Paradise Lodge & 6.19 & strike slip & 14.97 & 585.12 & 0.166 \\
\hline Chi-Chi & 1999 & CHY024 & 6.2 & strike slip & 19.67 & 427.73 & 0.068 \\
\hline Basso Tirreno & 1978 & Naso & 6.0 & strike slip & 17.15 & 620.56 & 0.150 \\
\hline Parkfield & 2004 & Parkfield-Stone Corral 2E & 6.0 & strike slip & 5.23 & 566.33 & 0.157 \\
\hline
\end{tabular}

Table 2: Selected model parameters for DHI model.

\begin{tabular}{|c|c|c|c|c|c|c|c|c|c|}
\hline Shape & $\begin{array}{c}\text { Primary } \\
\text { shape factor }\end{array}$ & $\begin{array}{c}\text { Secondary } \\
\text { shape factor }\end{array}$ & $\begin{array}{c}\mathbf{G}_{\mathbf{a}} \\
\left(\mathbf{k N} / \mathbf{m}^{2}\right)\end{array}$ & $\boldsymbol{\theta}$ & $\bar{\Upsilon}_{d}$ & $\bar{\Upsilon}_{1}$ & $\begin{array}{c}\overline{\mathbf{\tau}}_{1} \\
\left(\mathbf{k N} / \mathbf{m}^{2}\right)\end{array}$ & $\overline{\mathbf{Y}}_{2}$ & $\begin{array}{c}\overline{\mathbf{\tau}}_{2} \\
\left(\mathrm{kN} / \mathbf{m}^{2}\right)\end{array}$ \\
\hline Round-shape & 36.4 & 4.26 & 579.57 & 0.4598 & 0.4181 & 0.03591 & 1570.04 & 0.5 & 230.46 \\
\hline
\end{tabular}


Table 3: First three modes of the base structure before and after adding bearings.

\begin{tabular}{cccc}
\hline $\begin{array}{c}\text { Structure } \\
\text { typelMode }\end{array}$ & $\begin{array}{c}\mathbf{1}^{\text {st }} \text { mode } \\
(\mathbf{s e c})\end{array}$ & $\begin{array}{c}\mathbf{2}^{\text {nd }} \text { mode } \\
(\mathbf{s e c})\end{array}$ & $\begin{array}{c}\mathbf{3}^{\text {rd }} \text { mode } \\
(\mathbf{s e c})\end{array}$ \\
\hline $\begin{array}{c}\text { Without } \\
\text { HDRB }\end{array}$ & 0.638 & 0.529 & 0.389 \\
With HDRB & 1.972 & 1.870 & 1.535 \\
\hline
\end{tabular}

As shown in Table 3, primary modal periods of the base structure increased significantly after adding bearings to the base structure. This increase in the periods will reduce the maximum acceleration applied to the building. Moreover, HDRB elements are capable of absorbing the input energy to the building via their hysteresis performance under dynamic loading. For instance, shear force-shear displacement plots of one of the HDRB elements under Victoria and Chi-Chi earthquake ground motions are presented in Figure 8. As shown in this figure, the isolator successfully dissipated earthquake energy with minor lateral deformation. Moreover, input energy plots for the considered structure with and without HDRB

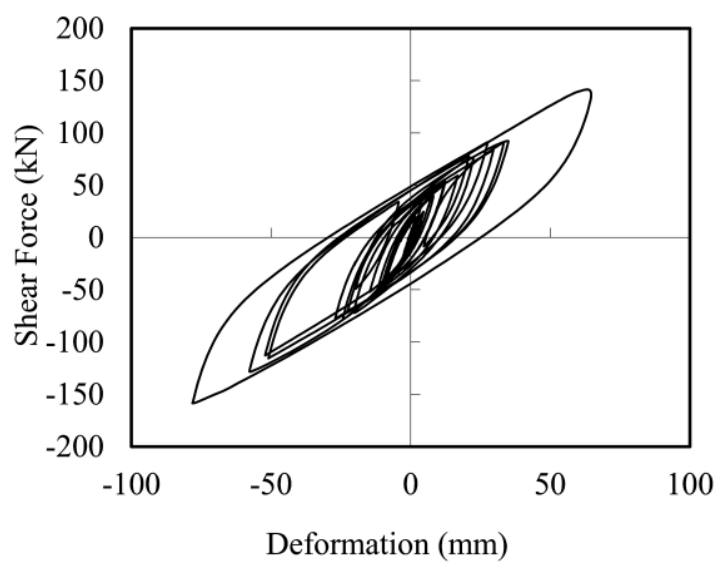

(a) isolators under the Basso Tirreno and Morgan Hill earthquake ground motions are illustrated in Figure 9.

By evaluating nonlinear time history analy sis results under both cases of with and without HDRB elements, it was obvious that the isolators enhanced the structural behaviour impressively. In the worst and best cases, the isolators decreased the base shear force by $61.8 \%$ and $92.2 \%$, respectively. Detailed results regarding the absolute maximum base shear forces and their reduction ratio are shown in Table 4 . Moreover, to better understand the advantages of adding HDRB to the base structure, the base shear force versus time results are presented in Figure 10 for two cases of with and without the isolation system under all seven ground motions. Improved behaviour of the isolated structure (i.e. decreasing base shear force and smoother trend) throughout the ground motion duration is observed for all ground motions. Another interesting output is the evolution of plastic hinges and the performance levels achieved by the vulnerable and rehabilitated buildings. As illustrated in Figure 11, in the rehabilitated building the structural elements mostly remained elastic and only few braces entered into the acceptable plastic region. Therefore, the rehabilitated structure can be argued to have satisfied the desired performance level (i.e. life-safety; LS) under all ground motions.

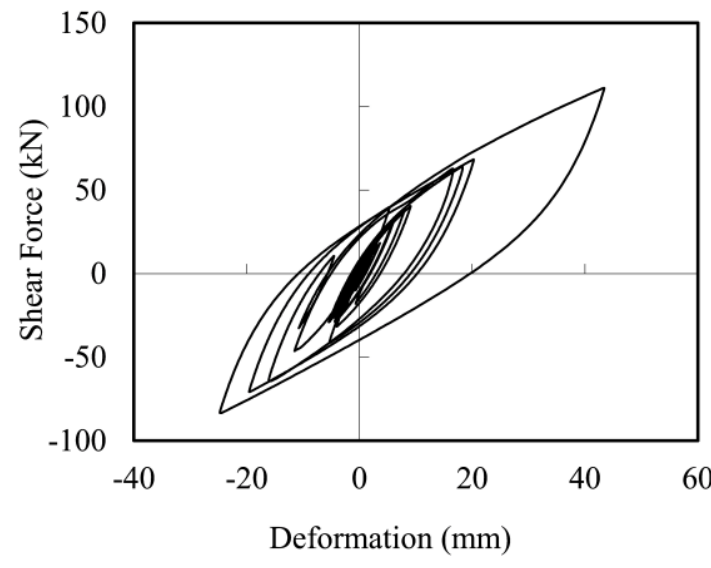

(b)

Figure 8: Shear force-lateral displacement relationship of HDRB element under Victoria (a) and Chi-Chi (b) earthquakes.

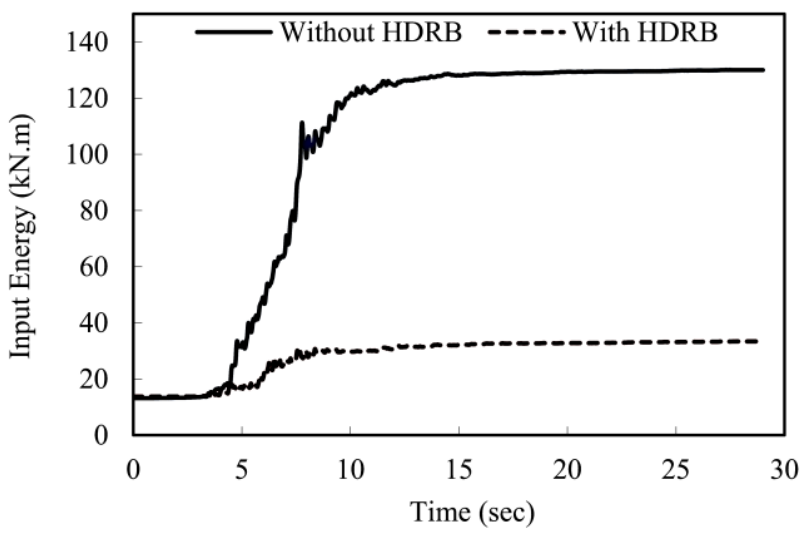

(a)

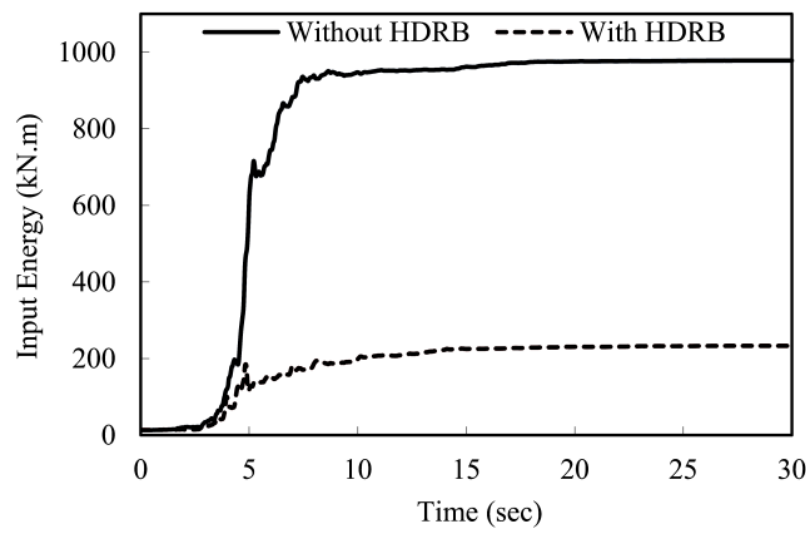

(b)

Figure 9: Input energy diagrams under Basso Tirreno (a) and Morgan Hill (b) earthquakes. 
Table 4: Absolute maximum base shear values and decreasing ratio.

\begin{tabular}{cccc}
\hline Event & \multicolumn{2}{c}{ Maximum absolute base shearforce (kN) } & Decreasing ratio $(\%)$ \\
\cline { 2 - 4 } & Without HDRB & With HDRB & 86.2 \\
Helena & 1059.3 & 146.9 & 85.2 \\
Victoria & 6282.6 & 935.1 & 92.2 \\
Morgan Hill & 4645.0 & 363.5 & 61.8 \\
Chalfant Valley & 742.0 & 283.9 & 64.1 \\
Chi-Chi & 1203.5 & 432.5 & 88.3 \\
Basso Tirreno & 1697.8 & 284.1 & 73.4 \\
Parkfield & 760.3 & 202.5 & \\
\hline
\end{tabular}
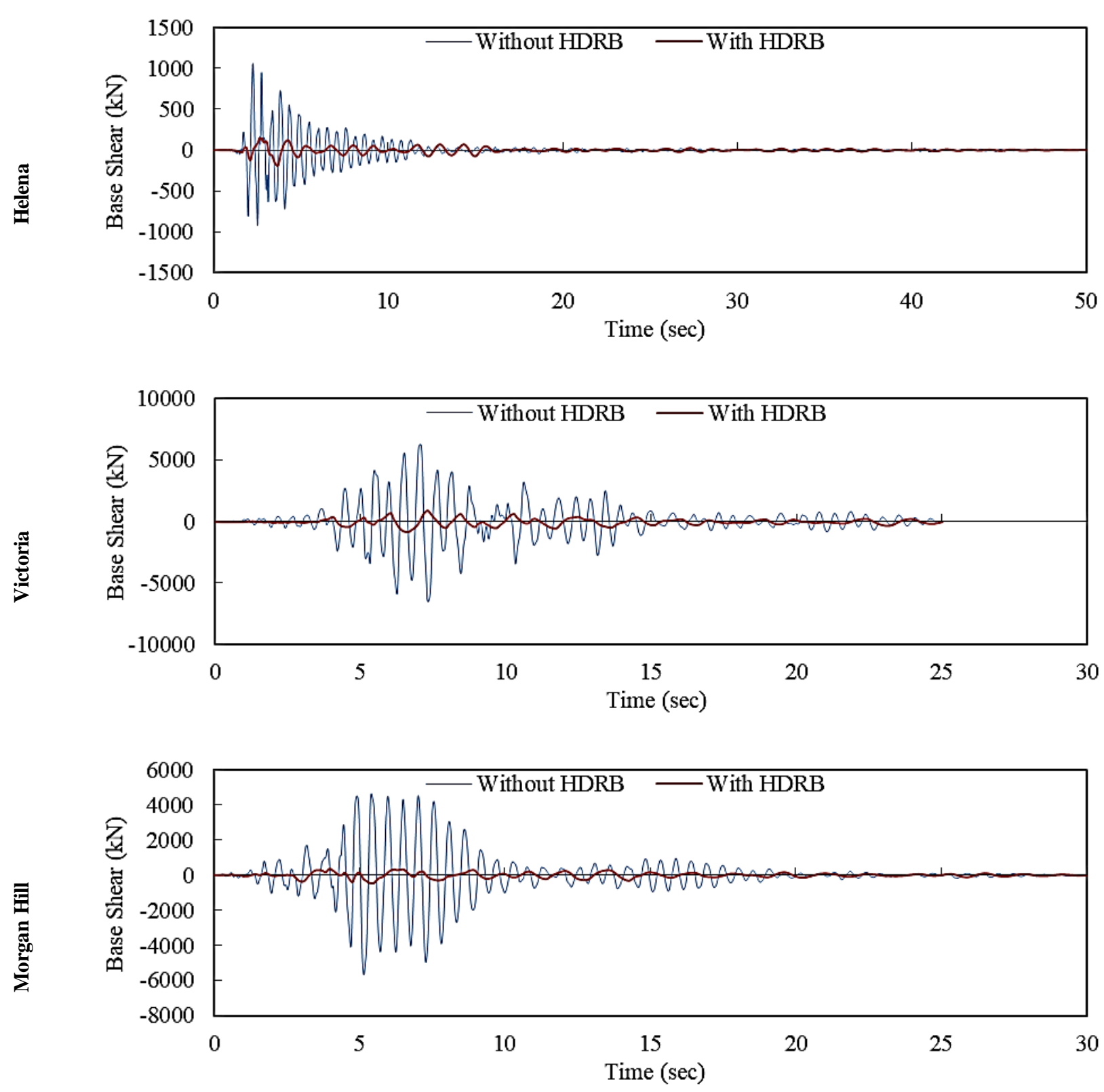

Figure 10: Base shear force versus time plots (Continuous). 

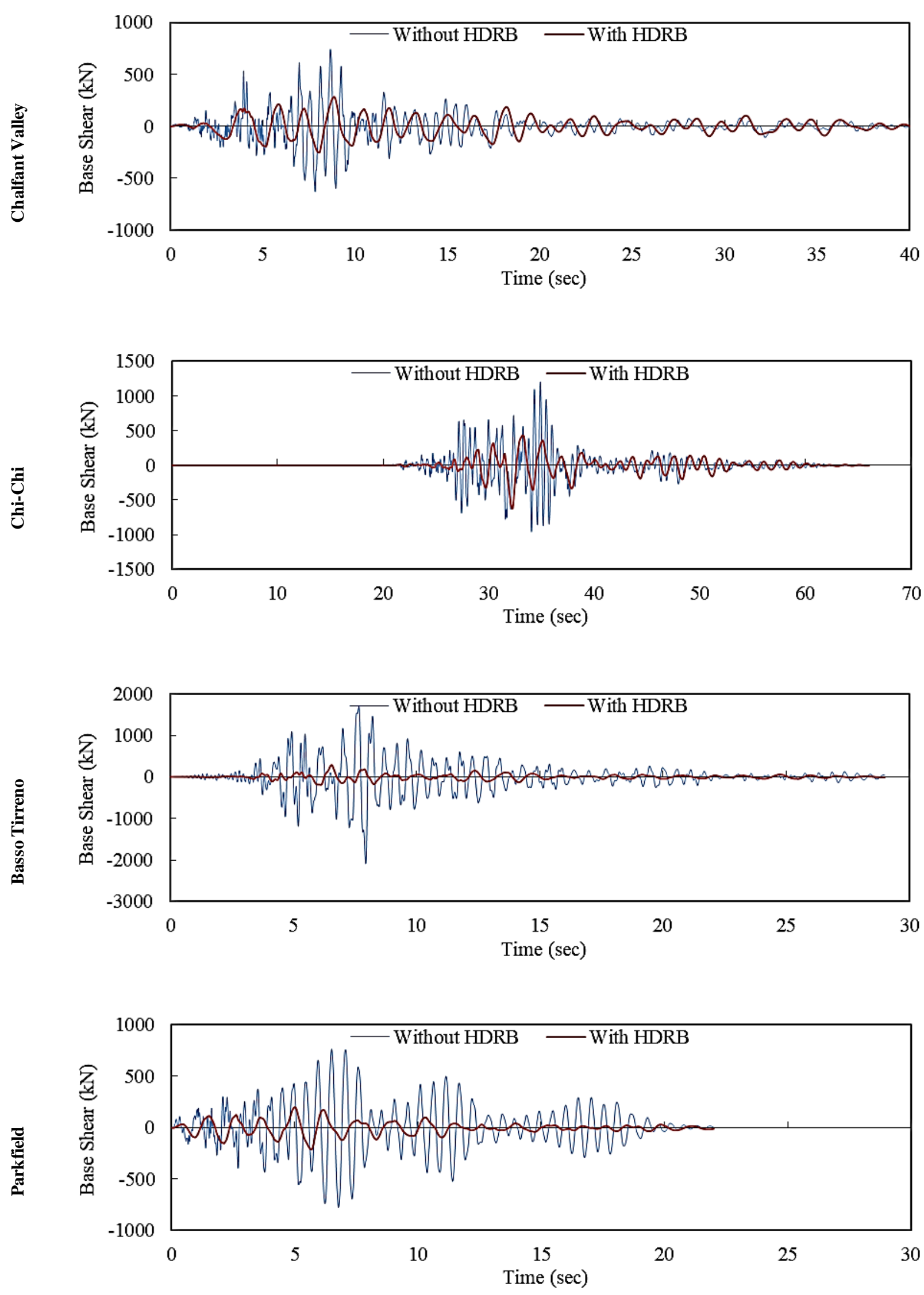

Figure 10: Base shear force versus time plots. 
Without HDRB
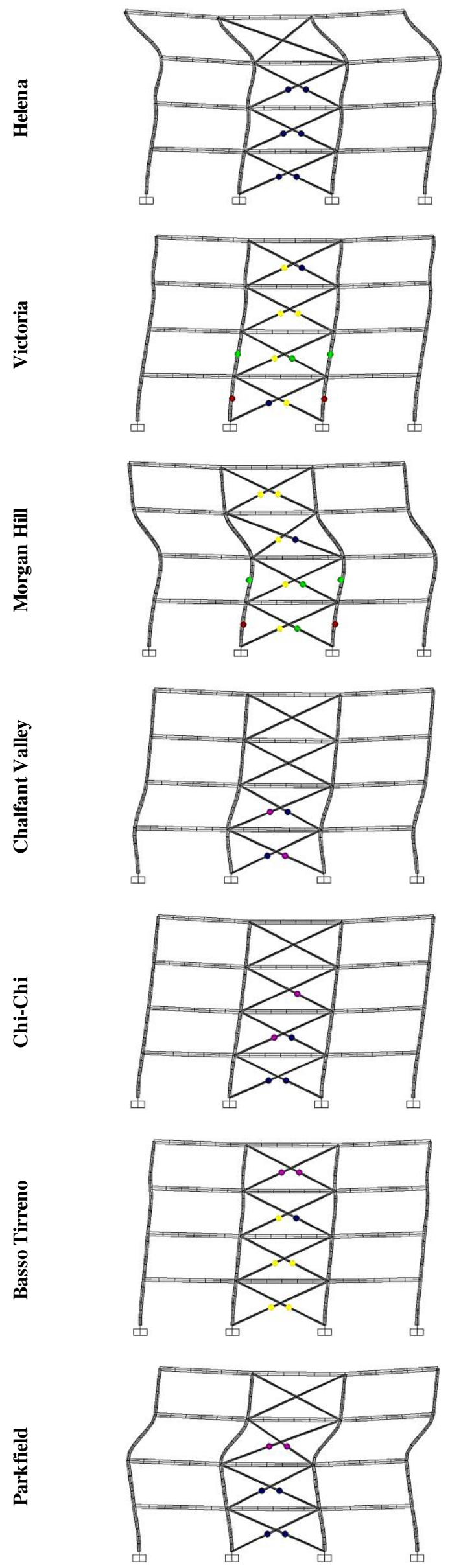

With HDRB
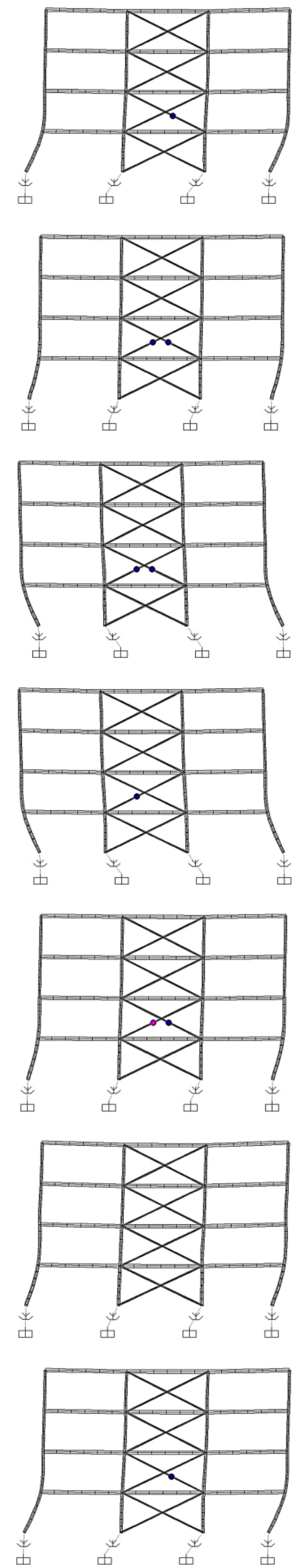

Figure 11: Base structure before and after rehabilitation (these plots are scaled 20 times for better visualization). 


\section{CONCLUSIONS}

A vulnerable four-story steel concentrically braced frame residential building situated in a seismically active region was rehabilitated using high damping rubber bearing (HDRB) isolation system. The vulnerable and rehabilitated buildings were modelled using plastic hinge elements and nonlinear three-dimensional time-history analyses were conducted in a finite element software using seven pairs of representative ground motions. It was observed that behaviour of the vulnerable building improved remarkedly after adding the HDRB bearings. Modal periods of the rehabilitated building increased as the isolators reduced the stiffness and the earthquake energy was dissipated effectively via the hysteretic response of the bearings. Furthermore, the absolute maximum base shear values induced by all ground motions decreased significantly $(61.8 \%-92.2 \%)$. The structural elements of the isolated structure remained mostly elastic and satisfied the lifesafety (LS) performance level under all ground motions.

\section{REFERENCES}

1 Derham CJ, Kelly JM and Thomas AG (1985). "Nonlinear natural rubber bearings for seismic isolation". Nuclear Engineering and Design, 84(3): 417-28. https://doi.org/10.1016/0029-5493(85)90258-4

2 Naeim F and Kelly JM (1999). "Design of seismic isolated structures: from theory to practice". John Wiley \& Sons, Inc.

3 Jankowski R (2003). "Nonlinear rate dependent model of high damping rubber bearing". Bulletin of Earthquake Engineering, 1(3): 397-403. https://doi.org/10.1023/B:BEEE.0000021512.74990.45

4 Tsai CS, Chiang TC, Chen BJ and Lin SB (2003). "An advanced analytical model for high damping rubber bearings". Earthquake Engineering and Structural Dynamics, 32(9): 1373-87. https://doi.org/10.1002/eqe.278

5 Yamamoto $\mathrm{M}$, Minewaki $\mathrm{S}$, Yoneda $\mathrm{H}$ and Higashino $\mathrm{M}$ (2012). "Nonlinear behaviour of high-damping rubber bearings under horizontal bidirectional loading: full-scale tests and analytical modeling". Earthquake Engineering and Structural Dynamics. 41(13): 1845-60. https://doi.org/10.1002/eqe.2161

6 Markou AA and Manolis GD (2016). "Mechanical models for shear behaviour in high damping rubber bearings". Soil Dynamics and Earthquake Engineering. 90: 221-6. https://doi.org/10.1016/j.soildyn.2016.08.035

7 CSI (2017). "Technical Note, High-damping Rubber Isolator Link Property". Computers and Structures, Inc. https://wiki.csiamerica.com/download/attachments/200540 69/S-TN-LNK-001.pdf?version $=1 \&$ modificationDate $=150$ $\underline{3622025261 \& a p i=v 2}$

8 Simo JC (1987). "On a fully three-dimensional finite-strain viscoelastic damage model: formulation and computational aspects". Computer Methods in Applied Mechanics and Engineering. 60(2): 153-73. https://doi.org/10.1016/00457825(87)90107-1

9 Kato H, Mori T, Murota N, Suzuki S and Kikuchi M (2012). "A new hysteresis model based on an integral type deformation-history for elastomeric seismic isolation bearings". 15th World Conference on Earthquake Engineering (WCEE), Lisbon, Portugal.

10 Mori T, Kato H, Nakamura M, Masaki N, Murota N and Kasai K (2014). "Hysteresis model of deformation-history integral type for Isolators". Proceedings of the 5th Asian Conference on Earthquake Engineering (ACEE), Taipei, Taiwan.

11 Kato H, Mori T, Murota $\mathrm{N}$ and Kikuchi M (2014). "Analytical model for elastoplastic and creep-like behaviour of high-damping rubber bearings". Journal of Structural Engineering, 141(9): 04014213. https://doi.org/10.1061/(ASCE)ST.1943-541X.0001181

12 Masaki N, Mori T, Murota N and Kasai K (2017). "Validation of hysteresis model of deformation-history integral type for high damping rubber bearings". Proceedings of the 16th World Conference on Earthquake Engineering (WCEE), Paper 4583, Santiago, Chile.

13 Kasai K, Mori T, Masaki N and Murota N (2018). "Simplified modeling for two-directional behaviour of high damping rubber isolation bearings". 11th US National Conference on Earthquake Engineering, Los Angeles, California.

14 FEMA (2005). FEMA 440: Improvement of Nonlinear Static Seismic Analy sis Procedures. FEMA, Redwood City, California.

15 Vatanshenas A, Heydarian H and Tafreshi ST (2018). "Seismic rehabilitation by steel jacketing method affected by different base support conditions using pushover analysis". American Journal of Engineering Research (AJER), 7(5): 208-212.

16 Vatanshenas A, Sharif Bajestany D and Aghelfard A (2018). Guidelines to Select and Scale Earthquake Records for Time-History Analysis of Structures. Salehian Publications. ISBN: 978-622-214-003-8. http://opac.nlai.ir/opac-prod/bibliographic/5378497 